\title{
Beautiful Face, Beautiful Place: \\ Relational Geographies and Gender in Cosmetic Surgery Tourism Websites
}

Ruth Holliday, David Bell, Kate Hardy, Emily Hunter, Meredith Jones, Elspeth Probyn, Jacqueline Sanchez-Taylor

\begin{abstract}
Cosmetic surgery tourism is a significant and growing area of medical tourism. This paper explores the gendered construction of cosmetic surgery tourism in different geographical locations through an analysis of destination websites in Spain, the Czech Republic and Thailand. We examine the ways in which gender and other intersections of identity interact with notions of space, place and travel to construct particular locations and cosmetic surgery tourist experiences. The relational geographies of skill, regulation and hygiene in discourses of cosmetic surgery risk are also explored. We conclude that accounts producing cosmetic surgery tourism as undifferentiated experience of 'nonplace' fail to acknowledge the complex constructions of specific destinations in promotional materials targeting international consumers in a global marketplace.
\end{abstract}

Key words: cosmetic surgery; place; web sites; representation; tourism

\section{Introduction}

Cosmetic surgery tourism -- the movement of patients from one location to another to undertake aesthetic procedures -- is a significant and growing area of medical tourism (Reisman 2010). The UK's annual International Passenger Survey, produced by the Office for National Statistics, shows that approximately 100,000 UK citizens go abroad each year for medical treatment (a number rising by about $20 \%$ annually). Cosmetic surgery tourists are believed to make up about $85 \%$ of Australian medical tourists (Connell 2006). What's more, it has been suggested that although financial crises, privatization and the rising cost of healthcare may have slowed demand for cosmetic surgery in some developed countries, crossing national borders to procure those surgeries appears to be increasing as consumers seek out low-cost procedures abroad (see Bell et al, 2011).

This paper forms part of a multi-site research project on cosmetic surgery tourism looking at Britons who travel to Spain and the Czech Republic and Australians who travel to Thailand and Singapore and all nationalities travelling to South Korea. The larger project will follow tourists to their chosen destinations and fully investigate the cosmetic surgery tourist industries in all five destinations. In this article, however, we 
undertake the more modest task of examining cosmetic tourism websites from three destinations -- Spain, the Czech Republic and Thailand -- which are particularly popular with tourists from the UK (the former two countries) and Australia (Thailand). The internet is a key source of information for consumers researching their potential cosmetic surgeries, rivalled only perhaps by word of mouth (see Sanchez Taylor, 2011). Thus, the ways in which cosmetic surgery tourist websites appeal to and address their potential clients is an important part of researching this area. Before moving on to our website analysis, we first explore some key debates in the genderings and geographies of cosmetic surgery and medical tourism more generally. We then discuss the methods used to analyse the websites. Following this, we examine websites promoting three destinations in detailed case studies, identifying the specificities of their approaches to cosmetic surgery marketing to foreigners. We conclude that whilst some general motifs recur across different sites, significant national distinctions in the presentation of cosmetic surgery are also evident, and gender is central to this. Additionally, place is represented relationally through concepts such as surgical skill, hospital hygiene and risk, and specifically in terms of caring health professionals and the restorative properties of particular environments and landscapes.

\section{Cosmetic surgery tourism}

Due its highly gendered nature the practices and meanings of cosmetic surgery have become part of core debates within feminist theory. Women represent the majority of surgery patients, whilst the labour of surgery is a profoundly male occupation. ${ }^{1}$ Some writers have even claimed there is a 'Pygmalion' dynamic (Pygmalion refers to an Ovidian myth about a Greek sculptor who, disillusioned with real women, crafted a perfect woman from ivory and subsequently fell in love with her) at the root of this relationship, with male cosmetic surgeons fantasizing about sculpting the perfect woman (Jones, 2009). ${ }^{2}$ Furthermore, the motivations for having surgery are routinely attributed to pressure on women to conform to idealized forms of beauty. Whilst feminist work tends to disagree on whether women strive to achieve 'beautiful' bodies (Bordo 1993; 1997) or 'normal' bodies (Davis 1995), there is general agreement that aesthetic surgery exists within a misogynistic (beauty) culture, and only really affects women, and an exceptionally small proportion of deviant (feminized) men. In fact, Davis

\footnotetext{
${ }^{1}$ Men are estimated to constitute around 10 per cent of cosmetic surgery patients in 2010 (see for example the BAAPS or AAAPS), however, some of the surgeries they are most likely to have - cosmetic dentistry or hair transplants, are not included in the statistics. Men are generally excluded from discussions of this form of elective surgery.

${ }^{2}$ A current and poignant example of this can be seen in the Almodovar film, The Skin I Live In (2011).
} 
(2003) goes so far as to claim that the doctor-patient relationship is inherently gendered and that most men cannot submit themselves to the passive role that 'patient' entails. Men's procedures are still rarely mentioned in the cosmetic surgery literature, perhaps because 'official' statistics in the UK and US continue to hide men's treatments by excluding cosmetic dentistry and hair transplants. Figures on breast reductions -- the second most popular surgery in the UK and US -- are frequently assumed to apply only to women, despite Miller's (2005) claim that in the US over 80 per cent of these surgeries are actually performed on men. Gender, then, has been the predominant social category within which cosmetic surgery has been analysed.

In contrast to its centrality in analyses of cosmetic surgery, very little has been written in relation to gender in reference to cosmetic surgery tourism in particular. For example, Elliott's (2008) book depicts cosmetic surgery consumers as a highly mobile, wealthy elite - imagined as 'a couple'. Although he does not differentiate by gender, we could argue this international business traveller model, securing surgery to improve workplace competitiveness, is implicitly male. In Elliott's model it is the caring health worker in the surgical destination who is feminized by means of care, poverty and emotional labour (see also Casanova 2007). Sara Ackerman's (2010) intricately observed anthropology of cosmetic surgery tourists centres on women travelling to Costa Rica. She offers a real sense of what it might be like to be a tourist or care worker in that destination, as well as how the destination itself is marketed. Whilst Ackerman does not provide a gendered analysis, she does highlight the emotional labour performed by surgeons, in many ways challenging the masculine surgeon/ feminine patient binary. Finally, again challenging some earlier models of cosmetic surgery tourism, Meredith Jones pointed out in her research on Australians travelling to Thailand, that the female participants she interviewed were far from being embers of a global elite - instead they were mostly lower middle-class office workers (Jones, 2011). She also demonstrated the contradiction between the passive image of the cosmetic surgery client and the active and intrepid traveller to 'exotic' locations like Thailand. The cosmetic surgery tourist, then, is a complex and contradictory figure and one that warrants further investigation.

One further criticism we might make about the early cosmetic surgery tourism literature is its inattention to place. For some writers in this field there are only two places - the wealthy 'West' and the exploited developing country whose medical assets are incrementally stripped as cosmetic surgery tourism flourishes. The growing body of literature on cosmetic surgery in different geographical contexts has also tended to ignore particular national contexts and emphasize globalization as homogenization particularly the globalization of a single (Westernized) beauty ideal for women (see for example Davis, 2003; Kaw 1997; Woo, 2004). For example, for Eliott (2008), cosmetic 
surgery tourism is simply a product and/or driver of globalization. He seems to assume a homogenized, disembedded experience of place and of cosmetic surgery tourism as enclaved in restorative nonplaces. In fact, types of cosmetic surgery procedures are highly differentiated in different national contexts - buttock augmentation in Brazil, for instance, or cheekbone shaving and calf trimming in Korea. Some authors have positioned all surgeries outside the West as aiming to approximate a non-Western body to a Western one (for a critique of this position see Holliday and Elfving-Hwang 2012).

Although no sustained research has yet been conducted into cosmetic surgery tourism websites, some research has covered other promotional materials in medical tourism more generally. In relation to the use of medical tourism brochures, Crooks et al (2011) identified an emphasis on high-tech facilities and excellent clinical care and aftercare and a relative invisibility of cost/price in these materials, which they find surprising given the dominance of economic rationale in coverage of medical tourism. They suggest a number of explanations for this, including the difficulty of communicating a message about the combination of low cost but high quality services. However, a distinction was identified between promotional materials for facilitators/agents, which were more upfront in making price comparisons, whereas hospitals and clinics tended to trade on expertise and care.

In their thematic content analysis of medical tourism promotional materials, Crooks et al (2011) found that the most common images used were hospital exteriors, followed by 'non-photo images' (such as cartoons), images of clinical equipment, facility logos and general tourist/travel images such as images of beaches or historic sites of interest. At the lower end of their image count were staff photos, hospital interiors, images of bodies, and maps. While this research is useful, it must be remembered that cosmetic surgery tourism differs from other forms of medical tourism. Medical tourism may offer someone a new hip but cosmetic surgery tourism promises something more, a holistic experience and a dramatic change: a new 'you'. The discursive terrain of cosmetic surgery thus differs in important ways, connecting to discourses of 'self-esteem' and confidence (Edmonds, 2011) beyond the bio-medical realm. Thus, in analysing cosmetic surgery tourist websites it is important to look at the possibilities they evoke, and their co-constitutive intersections with discourses of beauty, bodies and success that in the past have linked to a specifically feminine narrative.

\section{Researching Cosmetic Surgery Tourism Websites}

The Internet has reframed tourist practice in important ways, not least by facilitating 
'virtual travel' and information- and image-gathering in the planning stages. Cormany and Baloglu (2011) argue that medical tourism is a particularly concentrated example of this, given that the expansion of medical tourism postdates the internet, and is heavily reliant on web based information. As they note, analysing medical tourism websites enables us to unpick both 'push' and 'pull' factors, moving away from an overemphasis on pricing as the main driver of travel. They argue that, as yet, the literature has not explored 'how this purpose of travel, which is the first tourism genre to have fully started in its modern form after the existence of the internet, has been facilitated, perhaps even essentially created, through the worldwide web' (Cormany and Baloglue 2011: 710). The same can be said for cosmetic surgery tourism; as we have argued elsewhere (Bell et al 2011), the Internet is stitched into the heart of cosmetic surgery tourism, and therefore must be a core consideration in any study of it. Understanding how websites project place (and service) image, and how that image may be interpreted by potential tourists, therefore constitutes a central part of our project.

There is now a well-established literature on the role of place images in the experiences of tourism, and a 'turn' towards visual methods more broadly in tourism studies (Rakic and Chambers 2012). Tourists draw such images from a range of 'official' materials, such as brochures and guidebooks, 'unofficial' sources such as popular culture, and past experiences, building up a sense of the place-to-be-visited and picking through different sources, selectively 'indexing' images and ideas (Rojek 1997). However, much of the research on destination image in tourism studies seeking to understand tourists' decision-making processes is quantitative and aims to advise on 'effective' place marketing. Unlike the upsurge in cultural and critical approaches to understanding websites and other online materials in other fields, tourism studies has imported its largely positivistic and quantitative methodologies into the virtual realm.

Nevertheless, useful work has emerged focusing on the particular ways in which tourism websites articulate, for example, national identity and ideas about national characteristics that are assumed to be positive 'attractors' for potential tourists (c.f. Furisch and Robins 2004; Choi et al 2007), and which look more closely at the ways in which 'virtual tourists' engage with websites as part of their overall tourism experience. Wilson and Suraya (2004) have considered the ways in which websites cultivate trust in potential tourists - through the use of 'welcoming' images, as well as text - encouraging online browsers to make aesthetic judgements about the places they are promoting. Websites function as 'aesthetic traps' seeking to grab the attention of those browsing online (Miller 2000), and as such they must engage viewers quickly if the site is not to be passed over. Clearly, what this means for approaching tourism websites as objects of research is a keen awareness of both production and reception. Official websites, like 
other forms of tourist promotion, therefore 'shed light on the values and desires of tourism promoters and tourists', and in doing so they can inform us not only about the destination, but also about the values and ideologies of their producers and consumers (Jokela and Raento 2012: 53; our emphasis).

We begin this paper from an understanding of the website as a multimodal genre. Its rise in the last decade can be seen as a distillation of the ways in which word and image are increasingly complementary in the semiotic landscape (Kress, 1998). The intertwining of word and image over the last sixty years has meant, according to Anne Cranny-Francis,

...the end of an older reading and viewing practice in which the visual was surveyed for its possible meanings and then a verbal translation was attempted. Instead the verbal and visual are interrelated to generate meanings (2005: 1011).

In multimedia, meanings are made and understood not merely through writing, through still images, and through sound and video, but also, crucially, through the ways in which these media intersect. Our analysis therefore focuses on websites as texts-inthemselves that merge writing, image and other media.

Without doing extensive audience surveys we can only acknowledge that texts have different meanings for different people in different contexts. This is all the more important when discussing digital products that are both created and received in multiple locations and situations. Gunther Kress (1998: 77) notes that within the 'technological context of electronic, multimodal, multimedia textual production' there are no stable discursive systems but rather 'a situation where multiple representational modes are brought into textual compositions'. It almost goes without saying that the interpretations offered below are contingent on our own cultural, social and class positions, that is, as middle-class, educated researchers who are (probably) not going to have cosmetic surgery. The multidisciplinary critical discourse analysis (CDA) used here draws upon a carefully chosen toolkit comprising tourism studies, semiotics, visual analysis and visual literacy, cultural studies, and media studies. This 'mixed bag' is necessary to explore a variety of visual and textual analyses in very specific social, cultural and geographic contexts.

\section{Choice of websites}


Our research began with web searches for cosmetic surgery tourism in our chosen destination countries - Spain, the Czech Republic, and Thailand - the most popular destinations for tourists from the UK and Australia respectively. A broad analysis of these sites was conducted noting similar themes such as colours, types of images, typical text and so on. Then individual websites were selected for their ability to both typify and in some senses accentuate characteristics of cosmetic surgery websites in English in that country, and these sites were analyzed in detail. We spent most time exploring the home pages of the sites, since these 'covers' are designed to grab the attention and imagination of potential tourists. We also explored some further pages (if this information was not on the home page) to look for representations of surgeons and surgical skill, and other important factors like post-operative care and accommodation. Overall, the three destinations included in our study, whilst sharing some similarities, presented fairly distinct national cosmetic surgery cultures. We have outlined our analysis of each country below and will subsequently discuss the similarities and differences between them. In particular we have foregrounded beauty, bodies, gender, place, skill and care as key themes that arose from the analysis.

\section{Spain}

'With its glorious climate, spectacular scenery and fine beaches, Spain has long been one of Britain's favourite destinations - for holidays, second homes and retirement. Now, the emergence of high quality clinics - coupled with the favourable prices - are making Spain important as a medical destination as well. The large expat population in Spain means that every kind of English speaking facility is readily available and the number of low cost flights from all British airports makes getting there easier than to almost any other European country' (http://netdoctor.privatehealth.co.uk/private-dentistry/cosmetic-dentistryabroad/spain/).

This description of Spain as comprising luxurious landscapes, familiarity, high quality and easy accessibility - both geographically and due to the predominance of English - offers a useful summary of the imagery and identity represented within cosmetic surgery tourism websites. Three typical websites (Cirumed - www.cirumed.es; Ocean Clinic www.oceanclinic.net; MillsMedical - http://www.millsmedical.com/marbella spain.asp) evoke images and feelings of luxury and relaxation, with home pages (in English) displaying beach resorts with up-market connotations. For example, Mills Medical (Marbella) features a marina shot, one of its headings announcing announcing 'life's a beach'. Cirumed's homepage features a header split between a woman's face and arms and an up-market marina, depicting a clear blue sky over a sea of expensive looking 
yachts and pleasure cruisers. These images serve to connect cosmetic surgery with beauty and success, specifically in the form of wealth.

Ocean clinic's (UK) home page banner also features the sea, with a large full width banner of a crashing wave cross cut with the words "Ocean Clinic- Beyond Beauty". Upon opening the site, ethereal electronic music plays with a woman's breathless voice singing, with the opening lines "make me... beautiful... perfect body, perfect mind, perfect face, perfect life". ${ }^{3}$ The lettering here is sans serif and curved, indicating both modernity and softness. It is purple/lilac, a colour often used in marketing internationally to connote womanhood and femininity. Such imagery, combined with the ethereality of the music, move the viewer away from any idea that this may be merely a 'surgical' site.

Upon selecting the language (the choice is between English, Spanish, German, French and Russian), a new page opens up in which the banner remains, now placed above the back of a young slim 'mixed-race' woman whose silhouette, turned slightly to one side, betrays the inexplicit outline of what many would consider a 'perfect' (although distinctly unaugmented) breast. Her arms are raised above her head, her fingers lazily playing with her braided hair tightly knotted at the back of her head. Oblique angles and shots from behind such as this convey feelings of both vulnerability and trust (Kress and Van Leeuwen 2006). The imaginary relation with this figure is one of both identification and idealization: the promise is that this 'perfect' and unobtainable body might just be graspable for the viewer given enough effort (and cosmetic surgery). To the left of this image is a list of surgeries ranging from facelifts, to breast augmentation, to liposuction, to facial feminization. The text connects 'youth', 'health' and 'contemporary image' with beauty and addresses patients who want to look 'beautiful and attractive while enjoying the psychological benefits of improved self-esteem and renewed confidence' (http://www.oceanclinic.net/plastic-surgery/). This will be delivered, the text promises, in superb and tranquil premises in beautiful Marbella. The beauty of the landscape is thereby connected with the beautiful bodies produced by the clinic.

On the right hand side of the homepage constantly shifting, close up, shadowy images of women's body parts - mostly breasts, thighs, stomachs, buttocks and faces (and none gazing directly at the camera) - in a variety of skin shades are interspersed with a bright image of Dr Kai O Kaye. Dr Kaye, who is German, has trained in Bonn, Paris, Los Angeles and Munich and is a registered consultant in Germany, Spain and the UK. A white man,

\footnotetext{
3 This is part of Engine Room's song 'A Perfect Lie', used as the theme tune of the popular US drama Nip Tuck (2003-2010) about a plastic and cosmetic surgery clinic in Los Angeles.
} 
probably in his mid-forties, he has shoulder-length hair and a short but imperfectly trimmed beard. He wears a suit without tie and stands facing front on, arms crossed assertively, with a direct gaze at the camera. Both text and image, then, mark him as a distinct and active individual in stark contrast to the generic images of women's body parts that surround him. This juxtaposition situates women as a collection of parts while men are whole, simultaneously positioning the surgeon as authoritative and patients as the passive objects of his (and our) gaze. The Ocean Clinic itself is pictured - in $\mathbf{3 6 0}$ degree view if required - along with some of its staff (who remain largely unnamed). All staff other than Dr Kaye are attractive and well-groomed but professional looking women. The clinic and consulting room are separated by a glass wall and sparsely furnished in a modernist 'international' style with Barcelona chairs. Fresh orchids lean lazily over the rims of the chic vases that contain them, reflected in the polished black granite of the floor tiles.

Whilst these depictions inevitably 'set the scene' for the surgical tourist's imaginary transformation, in fact the vast majority of imagery contained on the website consists of before and after shots. After the serenity and perfection of the generic images, these photos of actual patients are not only shocking but grossly interruptive of the surgical fantasy. We are brought quickly down to earth by seventy-year-old patients facelifted to look fifty and middle-aged men with their ears pinned back. Most of the actual patients are attractive in their own ways, but shockingly real compared with the airbrushed and phantastical representations of the homepage. Whilst all the generic images of 'beauty' are of women, Dr Kaye explains that $25 \%$ of his patients in 2009 were men and that this figure is increasing. In his blog he writes that he has close links to the Algarve Clinic, a sex reassignment centre in Marbella, and his specialism in face and neck surgery gives him particular expertise in facial feminization. But male and trans patients, whilst making up significant numbers of actual patients, are missing from the main promotional photography. Perhaps the connection of the feminine with beauty would be interrupted by the inclusion of these other patients, or their inclusion might alienate more 'traditional' patients.

\section{Czech Republic}

Cosmetic surgery tourism websites in the Czech Republic (La Derma www.laderma.com; Beautiful Beings www.beautifulbeings.co.uk) depart markedly from those of their Spanish counterparts. Most noticeably, in place of images, the home pages are dominated by text, prices are foregrounded and body parts are conspicuous by their absence. For instance, the most striking feature of the LaDerma Clinic homepage is a 
large red maple leaf overwritten with the words 'Canadian Plastic Surgery in Prague'. The clinic's banner includes four images, from left to right, featuring a picture of the clinic exterior, a consultation inside the clinic, a surgery in process (although the patient is hidden under scrubs and operating sheets) and a nightscape of floodlit Prague. These are all long shots, and far less personal or intimate than the close-ups used in the Spanish and Thai sites. They position the viewer as objective and somewhat transcendent. The text promises 'highly qualified plastic and aesthetic surgeons with many years of experience in the field of plastic and aesthetic surgery in Canada and the USA'. The 'lead' (perhaps only) surgeon is Dr. Cerna, a Canadian citizen, certified, the website assures us, to perform plastic and aesthetic surgery in the Czech Republic, the UK and Austria (although it is notable that Canada is not mentioned). In short, surgical skill is prioritized on the homepage and evidenced through its connection with other surgical destinations - Canada, the USA, Austria and the UK. Hygiene is also given prominence. LaDerma promises 'supra-septic conditions, disposable operating props, hygienic surgical dressing, absorbent suture' - reassuring perhaps, but also startlingly graphic.

The Beautiful Beings website positions Prague as,

the 'cosmetic capital' of Europe. The Czech Republic has a long tradition of plastic surgery; the Czech professor Francis Burian is regarded as one of the pioneers in the field of plastic surgery. Charles University, Prague was home to Europe's first faculty for plastic surgery which opened in 1920.

It therefore draws on historical precedent to establish Prague as a key site in cosmetic surgery culture. This is also reflected in the images and text which frequently emphasize the historic city of Prague and present images of old building facades. The clinic includes seven surgeons, two are from outside the Czech Republic and two are women. The banner is simple -- a lilac bar (note the purple tone again) across the page featuring the words 'Beautiful Beings: a holiday and a treatment rolled into one'. The Czech sites emphasize elements of both surgery and tourism, whereas the Spanish sites emphasize the experiential nature of the trip. Most notably, prices for popular surgeries are prominently displayed directly under the banner, in GBP -- 'Gastric Band £3980, Liposuction £1600, Nose Surgery £2146, Tummy Tuck \& Liposuction £2846’.

In the top left of the home page a slim woman in a white t-shirt bra raises her arms above her head to hold up her long tumbling blonde hair whilst smiling wryly towards the floor. The sensible bra and intelligent expression foreclose salacious readings of this woman's body even as her indirect gaze and state of semi-nudity invite us to look. As in 
La Derma, pictures of the clinic's interior are featured, white again but offset with bold primary colours - bright green flooring and bright red 'contemporary' armchairs adorn the consultation and waiting rooms. In contrast to the expensive yachts and orchids in the Spanish clinic, plants and trees hint at 'nature' as opposed to 'beauty' here. Cosmetic surgery is becoming increasingly popular and socially acceptable for both men and women, we are told. The clinic's clientele are depicted as youthful and modern and we see them engaging with both male and female staff in what are depicted as fairly reciprocal encounters and the viewer/potential client is positioned as independent, intelligent and equal.

To the right of the page a video lasting 3 or 4 minutes plays once after each refresh. The film begins with an introduction to the clinic from an English male voiceover. He assures us the technology used in the clinic is 'state of the art' and that the clinic practices a number of different types of medicine ranging from the medically necessary to cosmetic surgery and anti-aging medicine. 'Three hundred thousand satisfied customers' have passed through the clinic, which is the largest of its kind in Europe and is leading the world in its advanced use of laser techniques. The English voice then hands over to the clinic director who takes us on a tour of the operating theatres. The first theatre is 'so modern and hygienic' that the Director explains: 'we can make here the transplantation of heart' and there is 'zero risk of some infections'. Another theatre is designed for smaller procedures, such as the removal of small tumours or eyelid lifts, yet its hygiene is equivalent to the level required for much more complex procedures in some other clinics and hospitals. Returning once again to the British voiceover we are reassured that 'in the unlikely event that something goes wrong' the clinic has a fully equipped intensive care unit. And stringent industry regulation is better than most other countries in the world, where regulation is lax.

In addition to the modern hygienic clinic, accommodation for the duration of the stay and transfers from the airport can be booked via Beautiful Beings. $£ 55$ per night secures a four star hotel room and includes breakfast. The hotel also has a bar, restaurant, sauna and solarium. The city of Prague itself has a low profile on the clinic's homepage, but a link redirects the potential client to a description of the city as 'alive with fine restaurants, elegant hotels, fascinating sightseeing and first rate entertainment'. 'Carol's experience' on the testimonial page suggests that destination is an important factor:

I would like to thank you for your supporting phone calls while I was in Prague... Anyone having rhinoplasty can genuinely be told it is pain-free... My daughter had the operation some years ago in the UK and was given morphine and still remembers how painful it was. I actually spent two weeks walking and exploring 
the city, although I was wearing a plaster cast, I felt perfectly well and it was too good an opportunity to miss.

\section{Thailand}

Luxury is also clearly operationalised on Thai websites, albeit in a distinct way. Somnio Medical (www.somniomedical.com) poses the question: 'What better way to recover than in a 4-5 star accommodation? When the only thing you will need to do is pick up the phone and have your pillows and meals delivered (and have someone else do the housework daily!)'

(http://www.somniomedical.com/cosmeticholiday whychoosesomnio.html).

Within the Thai websites there was considerably more range, with some sites far more 'amateur' (www.mybodyandspirit.com.au) and others distinctly more sophisticated (see Somnio, analysed below). However, almost all include images of beaches, usually tropicalised through the use of images of long boats and palm trees and tanned, slim, youthful women in bikinis, and some men - especially male torsos. Also present, although less common, are images of groups of women poolside or shopping, women's and men's body parts in underwear, male patients, happy couples (always heterosexual) and surgeons (always men in white coats in a clinical setting). There are scattered images of actual surgeries, of Thailand's cities or urban areas, and of Thai people who are not medical professionals.

The lotus flower is nearly ubiquitous. Many sites also include images of massage and yoga, and pictures that evoke an 'Eastern spiritual' mood: faces with eyes softly closed in meditation, feet resting in pools of flowers, hands in the wai (prayer) position, Buddhist statues and temples. This holistic, ethereal, 'zen' representation is reflected in the first paragraph that a potential tourist encounters on the Somio website:

'In Latin Somnio means 'to dream' and at Somnio International Medical Holidays $^{\circledR}$, we take the guess-work and hard work out of assisting you in achieving your dream'.

This rather ethereal framing sits uneasily, perhaps, with a large table comparing prices for different procedures in Thailand and Australia. The front page also emphasizes more material advantages, such as 'worldclass hospitals, Internationally trained surgeons and doctors [and] state of the art medical facilities'. Much like the Spanish and Czech websites, the 'international' experience of the surgeons is pressed along with the 
importance of the regulation of the hospital (it conforms to the American JCl system -'one of the most advanced and demanding accreditation systems in the world'). In a reversal of conventional discourses on cosmetic surgery tourism, the manager Peter Davidson argues that risk is minimised by travelling abroad for surgery as, amongst other things, in terms of superbugs 'our infection rates are much lower than Australian hospitals'. Although value for money is emphasised, Thailand is described as an inviting, sensual, peaceful environment, promising 'dedication and "genuine" care from the doctors', including 'a friendly 'Thai' smile on every corner...' Key to cosmetic surgery marketing in Thailand ('the land of smiles') is the notion of care, notably the idea of 'genuine', 'sincere' or 'authentic' care from medical professionals. This, combined with the notion of a carefree, sensual holiday with a notable 'spiritual' element, forms the basis of advertising cosmetic surgery tourism in Thailand.

The Somnio website is professionally designed in a classic style with 'basic identifiers at top and bottom' (Cranny-Francis, 2005: 46). It is set against a pale green 'natural' looking wallpaper reminiscent of fresh bamboo, and a bamboo cane is used to separate the header from the information below. The word 'Somnio', appearing on every page, has been carefully crafted using a capital sans-serif font (connoting the modern/technical) with curved edges (connoting serenity and softness). The first ' $O$ ' in Somnio is the company logo. Larger than the other letters, it contains a stylized crescent moon that is reminiscent of the yin/yang symbol as well as two stylized leaves that seem to 'grow' out of the ' $O$ '. This cleverly implies peace, growth, the earth and the moon, thus subliminally linking cosmetic surgery with nature and harmony rather than with sutures and scalpels. Twenty-one images in sets of three rotate in the header, and appear at the top of every page. They comprise two Buddhas, three 'nature shots' (leaves, beaches), three pictures of people in yoga or meditative poses, and thirteen images of 'bodies beautiful'. Of these, three are men.

The remaining ten images are all of women's body parts - as in the Spanish site there is no complete body-and five of the images are extreme close-ups. The extreme close-up denotes "the distance at which "one can hold or grasp the other person" and therefore also the distance between people who have an intimate relation with each other' (Kress \& Van Leeuwen, 2006: 124). We suggest that the extreme close-ups of body parts on this site and others like it indicate bodies that are graspable and achievable (bodies we can touch or become). These representations also act as pseudo mirror-images (in which we are invited to imagine that the body parts are in fact our own). These breasts, buttocks, eyes and lips are framed so they are not connected to whole people but are rather products on display, products that may be acquired. Where a face is shown the gaze is passive and/or indirect, in line with most mainstream images of women 
(whereas most popular media images of men feature a direct/active gaze, as indeed do two of the three on this site). Body parts, including some obviously augmented breasts, are set against plain white or beach/pool backgrounds, thus aligning the surgical experience with the holiday experience (the company's facebook page even features, somewhat incongruously, a picture of a Buddha statue on the click-through for 'accredited hospitals'). Indeed, we argue that this site emphasizes the holiday experience more than the surgical one. In marrying the two so seamlessly it implies that a fabulous holiday is intricately intertwined with surgery: one is not possible without the other. It offers a fantasy, not just of achieving a body or face that will be considered by many to be beautiful, but of inhabiting a space of tranquility and wellness... the body here is a 'landscape' to be inhabited as much as the nature shots are; both offer ideal fantasy spaces.

Finally, noting the quote at the beginning of this section, it is fascinating that 'somnio' means 'to dream' in Latin. The care taken to choose such a meaningful name points to a sophistication in marketing that renders company names like 'Gorgeous Getaways' and 'Beauty Escapes' rather crude and old-fashioned. Perhaps cosmetic surgery tourism marketing is coming of age.

\section{Gendered Geographies}

The gendered geographies of the websites we selected are impossible to overlook; representations of women and men differed sharply between the different destinations. For example, women are featured on the Spanish websites primarily as body parts interestingly, unaugmented body parts. We might argue that these fractured images stand in for the fracturing of the woman's subjectivity, a subjectivity ironically made whole again by the surgeon's knife. On the Cirumed site the surgeon himself is represented as a whole (centred) subject as he stands square and gazes into the camera's lens. The visual discourse of fracturing seems to link closely with the text. Cirumed states that clients want to 'look more beautiful and attractive while enjoying the psychological and spiritual benefits of improved self esteem and confidence', so beauty is explicitly linked to self-esteem for women in the first written sentence on the site's homepage. The surgeon's knife completes the woman and restores her selfesteem. This is echoed in Alex Edmonds' (2010) study of Brazilian cosmetic surgery where the discourse of self-esteem is firmly embedded in clinical narratives, combining beauty and self-confidence in the concept of 'aesthetic health'. As one surgeon in Edmonds' study joked 'What is the difference between a psychoanalyst and a plastic 
surgeon? The psychologist knows everything and changes nothing. The plastic surgeon knows nothing but changes everything' (2010: 76).

In sharp contrast to the Spanish sites, Czech clinics represent both patients and surgeons as women and men. There is very little emphasis on body parts or before and after pictures, foregrounding instead waiting and consultation rooms, theatres and equipment. Czech websites emphasise skill, hygiene and regulation. This practical, information-led and sterile approach is fundamentally different from the exotic, evocative and eroticised version of cosmetic surgery offered by Spanish and Thai websites. Of course, these have to be read in terms of the different national surgical cultures in which the clinics are based, but they also seem to betray class preferences. Tourists to the Prague clinics are addressed as largely gender neutral, highly informed clients who are able to talk over the possible risks of their surgery with their local GP. They are assumed to be astute and demanding consumers who have high levels of cultural capital and are accordingly addressed as full (whole) subjects. No reference to self-esteem is made, instead clients might undertake surgery for 'different reasons' (we might say practical reasons) including wanting a 'younger, fresher look' or 'relief from back pain' or 'getting your body back in shape after child birth'. In comparison, the orchids and yachts of the Spanish sites can be taken as rather clunky signifiers of status and luxury recognizable to those who don't possess it. 'Nature', on the other hand, is reliably, almost imperceptibly, entangled with middle-class values and morality especially middle-class beauty (see Holliday and Sanchez Taylor, 2006). Middle-class clients are more likely to be fully informed about risk, since their bodies/lives are extremely valuable already. Working-class patients may be attempting to accrue value through beauty itself when other sources of capital have been kept firmly beyond their grasp (Skeggs, 2003).

We suggest that in some ways, Thai sites represent a kind of hybrid between Spanish evocation and Czech practicality, but additionally they foreground what we might call 'holistic well-being'. Rather than addressing the wealthy, they address the aspirational with a promise of 'luxury you can't get at home'. As Meredith Jones notes about cosmetic surgery tourists she interviewed in Thailand in 2009, many

'felt they were being treated like royalty or celebrity, and this change of status was a key part of the cosmetic surgery tourism experience for them... The selfimprovement that cosmetic surgery promises is foreshadowed and enhanced for cosmetic surgery tourists in Thailand and many other destinations because, for a brief time in a foreign land, they are part of a privileged class: they are rich, elite and pampered' (2011, forthcoming). 
In this case, Thai websites seeks to offer cosmetic surgery tourists experiences that exist outside their usual class limitations.

The last paragraph on Somnio's home page encourages potential tourists to 'take the next step and change your life' and 'dream, believe and achieve great things'. This holistic version of well-being, though not directly about 'confidence' is related to the idea of self-esteem. Again, both Alex Edmonds and Sara Ackerman, in Brazil and Costa Rica respectively, note the propensity of middle-class (women) cosmetic surgery patients to take up other 'mind, body and soul' techniques, from New Age healing to psychoanalysis. The 'spiritual' is a highly feminised discourse in the West. Whilst Edmonds is careful not to celebrate cosmetic surgery discourse, especially its tendency in Brazil to psychologize social characteristics like poverty as 'low self esteem', he concedes that it does offer certain challenges to a masculinist clinical discourse that insists on a Cartesian mind/ body split. 'Aesthetic health', he argues, insists on a more holistic (and feminized) form of healthcare that originates from patients and which 'plastica' surgeons have been forced to acknowledge and adopt.

\section{Relational geographies of cosmetic surgery tourism}

All of the sites in our study share certain characteristics, such as a downplaying of pain and an emphasis on comfort, relaxation, and restoration. While we could argue that a focus on yoga, wellness, peacefulness, serenity, and spirituality in Thai websites, for example, is an obfuscation of the gory reality of the opened body in surgery, it is notable that the same motifs of relaxation are not used on all sites.

Far from homogenized cultures of cosmetic surgery, the three destinations show distinct marketing strategies relating to place branded identities and cultures of surgery. However, these do not constitute discrete places or countries, but are mutually dependent for national surgical identities on differences from and connections to other destinations or points of departure. Much like cities, spaces of cosmetic surgery appear to be 'imbroglios of flows and networks' (Jones 2009: 488) -- less like fixed points, more like concentrations of processes. In the commercial world of cosmetic surgery tourism -and indeed in tourism more broadly -- comparison and relations are core business. As time-space is compressed (Harvey 1989) by cheap air travel, consumers of cosmetic surgery are offered ever more choice. Choice means picking between different things that must make themselves distinctive through invoking distinctions and comparisons. As we have found in this research, there are a number of important and often quite 
nuanced ways in with both relationality and comparison are deployed to attract tourists to cosmetic in particular places.

Exploring how place, people and product (or service) are co-constituted and comarketed is something that has interested economic geographers (eg Molotch, 2005; Pike, 2011). Here, in the context of cosmetic surgery tourism, we can also see how the relational and comparative dimensions of these processes play out. We can pay attention to why any particular place 'has found itself situated next to, and compared with, all manner of other places' (Ward 2009: 472). As we have noted previously (Bell et al 2011), the principal elements of relation/comparison are: cost, access, quality and service (see also Schult 2006).

In common with other forms of medical tourism, costs of procedures were hidden or obscured in Spanish websites. This is explained through an extract from Dr Kaye's blog on a Spanish website, where he explains that unlike the cheap surgery offered by Brazil or Asia (due to their 'low wage economies'), Spain cannot compete on cost. Instead he highlights excellent food and beautiful beaches as attractive for cosmetic surgery tourists. However, cost takes centre stage in Czech websites with prices for procedures quoted in the target audience's currency. Prices are also easily located on Thai sites. Overall, cost comparisons with prices for the same procedures "at home" were fairly common outside Spain. Overall, then, cost can only be made an attractive driver when cheap surgeries can be facilitated by local economic factors and international exchange rates. Inability to compete on cost can push clinics and agents to highlight other benefits highlighted in relation to a different set of countries - for Spain, for example, as not as cheap as Asia or Brazil but better than the UK because of the relaxing and luxurious setting.

Access tends to speak more of relations or linkages, for example travel times, cost of flights, and familiarity of the locations of clinics, but access also extends to issues such as language - a location which offers English language staff may be more "accessible" to a UK tourist even if it is geographically far away. The act of travel itself is a form of relationality, and possibly part of the experience that distinguishes cosmetic surgery tourism from cosmetic surgery at home. Mobility involves a relation between sites of departure and arrival, a spatiotemporal experience of movement, and a series of imaginings - such as travel as 'glamorous'. The extent to which travel is made visible or invisible on cosmetic surgery tourism websites is therefore something to consider: is travel talked about in terms of convenience and proximity, or in terms of difference, adventure, and intrepidness? Interestingly, whilst Thai websites highlight the benefits of an 'exotic' location, a short film on Somnio website shows the Australian International 
Manager (Peter Davidson) of Phuket Hospital visiting potential clients in an Australian location. He is a white Australian living and working in Thailand. He has 'popped home' to deliver a lecture on the facilities of the Thai hospital in which he works. He doesn't just sell the benefits of the hospital in terms of cost, quality and service, he embodies its access/ proximity.

As noted in the case studies, comparisons do not only operate around lower costs and value for money, but also importantly, quality and service. Quality here is most frequently made concrete in terms of surgical skill, which in all the websites was represented as the most important driver of choice. However, this presents the problem - how can one decipher, from a website, the skill of a surgeon? Interestingly, skill was also marked in relation to space - that medical staff in one location have been trained or have worked at another place which has a good reputation for producing skilled medics (for example Czech Surgeons trained in Canada or South Africa, Spanish Surgeons trained in Germany or accredited to work in the UK or US and Thai surgeons who have worked or researched 'internationally'). The surgeon thus comes to embody the place-connections associated with 'modern' technology and expertise and therefore generates associations of skill and trust.

In addition to these global linkages, the websites frequently refer to national frameworks for regulation in order to offer reassurance and emphasize quality. As well as stressing equivalence - "our service is as good as you can get at home", for example a Spanish surgeon is licensed to practice in the UK (unsaid: but Spain has the food, climate and beaches you don't have in the UK) -- comparisons are also used competitively --"our service is better than you can get at home" -- there are no superbugs in Thailand, the theatre used in the Czech republic is also used for heart transplants (unsaid - unlike the dirty and second-rate facilities you have in the public healthcare system in Australia and the UK). Websites are frequently available in a number of different translations, targeting distinct markets, and often include reassurances about the language(s) spoken by staff to make the destination more homely. Thus, 'home' often features as an unspoken, absent other, not overtly referenced. As Schult (2006) writes in his guidebook to cosmetic surgery tourism, it's important for tourists to be able to decide how different (and we might add, in which ways) they want their cosmetic surgery tourism to be from 'home'.

As Wilson (2011) writes, in the context of medical tourism more broadly, in many cases it is the scale of the nation that is most prominently articulated, with national characteristics parlayed to attract tourists (see also Ackerman 2010). While this is patently true in the case of, for instance the idea of the authentic caring qualities of an 
entire nation, cosmetic surgery tourism destinations also trade on local specificity. They focus on the attractions of the particular city or resort, the 'historic' city of Prague or the luxurious restfulness of the marina in Marbella. In such places, already noted for their touristic experience, the tourism-ness of the experience might be emphasised, making cosmetic surgery tourism an unremarkable variant on ordinary tourism and therefore more 'imaginable'. Thus spatial scales interact relationally to produce a variegated geography of cosmetic surgery and of cosmetic surgery tourism, not a globally homogenous experience as is often suggested. As Ackerman shows, Costa Rica is marketed as a 'healing place', its landscape integral to successful recovery. All of our destinations in some senses link beautiful outcomes of cosmetic surgery to beauty in the surgical tourist destination. Cross-border flows of people, medical equipment and medical staff do not, therefore, equate to placelessness, fluidity or a "flat ontology". Instead, they present a vivid exemplification of 'phase space' (Jones 2009: 489), a space defined precisely by flows and places.

What we see in cosmetic surgery tourism websites is a complex folding together of place, people and products (or service). These concepts operate at various scales place represents the local, national and international. People are depicted as (i) generalized, in the form cosmetic surgery patients with low self-esteem, or 'gentle smiling Thais' who will care for them; (ii) individual surgeons or agents, for instance; and (iii) dissected body parts - both beautiful and idealized and, in more visceral terms, as before and after shots. While cosmetic surgery tourism websites might not be fully articulating a coherent place 'brand', they are nonetheless seeking to align place, people and product (see Papadopoulos 2011). While aspects of the brand are brought (or bought) in from elsewhere - such as medical training in a global centre of excellence, or confirmation of medical standards by a national body - it is only in the destination being promoted that all elements come together, in place, to produce the cosmetic surgery tourism experience.

\section{Conclusion}

In contrast to other accounts of cosmetic surgery tourism, with their emphases on globalization, homogenization and placelessness, we have traced instead a series of relational geographies and scalar patterns. Quality of one destination is always, we argue, invoked by reference to other places. This is not to deny the entangling of cosmetic surgery tourism in manifold global flows; it is, instead, to note local, regional, national and continental scales as important to the positioning of cosmetic surgery tourism destinations. 
Our analysis has also explored the genderings (and classings and racings) of cosmetic surgery tourist websites and how these gendered representations link to spatial scale. Nations, we have found, are feminized in terms of 'caring' or 'spiritual' characteristics associated with certain destinations. The local landscape is linked to surgical bodies through the tropes of 'beauty' and 'restoration'. Doctor-patient relationships are represented as highly gendered, or as genderless, betraying the class of the clients they target and linking nation to gendered characteristics like the erotic, the exotic or gender-neutral practicality. Perhaps the latter will make 'access' easier for men's surgeries too.

In the next phase of our research we will move beyond analysis of representations and into fieldwork that will investigate the practices of cosmetic surgery tourists, surgeons, and the multifarious workers in the cosmetic surgery tourism industry. Thus further publications will aim to compare the representations analysed above with actual material and corporeal flows, processes and networks. 


\section{References}

Ackerman, S. (2010) Plastic paradise: transforming bodies and selves in Costa Rica's cosmetic surgery tourism industry, Medical Anthropology 29(4): 403-23.

Bell, D., Holliday, R., Jones, M., Probyn, E. and Sanchez Taylor, J. (2011) Bikinis and bandages: an itinerary for cosmetic surgery tourism, Tourist Studies xxxx

Casanova, E. (2007) 'The Whole Package: Exploring Cosmetic Surgery Tourism', paper presented at the American Sociological Association annual conference, New York.

Carey, J. (1989) Communications as Culture: Essays on Media and Society, Routledge, New York

Choi, S., Lehton, X., and Morrison, A. (2006) Destination image representation on the web: content analysis of Macau travel related websites, Tourism Management 28: 11829

Connell, J. (2006) 'Medical Tourism: Sea, Sun, Sand and ... Surgery', Tourism Management 27: 1093-1100.

Cormany, D. and Baloglu, S. (2011) Medical travel facilitator websites: an exploratory study of web page contents and services offered to the prospective medical tourist, Tourism Management 32: 709-716

Cranny-Francis, A. (2005) Multimedia, Sage, London

Crooks, V., Turner, L., Snyder, J., Johnston, R. and Kingsbury, P. (2011) Promoting medical tourism in India: messages, images, and the marketing of international patient travel, Social Science \& Medicine 72: 726-32.

Davis, Kathy (1995) Reshaping the Female Body: Dilemmas of Cosmetic Surgery, London: Routledge.

Davis, Kathy (2003) Dubious Equalities and Embodied Differences: Cultural Studies on Cosmetic Surgery. Lanham, MD: Rowman \& Littlefield.

Elliott, A. (2008) Making the Cut: how cosmetic surgery is transforming our lives (London: Reaktion) 
Fursich, E. and Robins, M. (2004) Visiting Africa: constructions of nation and identity on travel websites, Journal of Asian and African Studies 39: 133-152

Heyes, C and Jones, M (2009) Cosmetic surgery: a feminist primer, Aldershot: Ashgate.

Herod, A. (2010) Scale (Abingdon: Routledge)

Holliday, Ruth and Jacqueline Sanchez Taylor (2006), 'Aesthetic surgery as false beauty', Feminist Theory 7 (2): 179-195.

Jokela, S. and Raento, P. (2012) Collecting visual materials from secondary sources, in Rakic, T. and Chambers, D. (eds) An Introduction to Visual Research Methods in Tourism (Abingdon: Routledge) pp. 53-69

Jones, M. (2009) Phase space: geography, relational thinking, and beyond, Progress in Human Geography 33(4): 487-506

Jones, M. (2011, forthcoming) 'Clinics of Oblivion: Makeover Culture and Cosmetic Surgery Tourism', Portal: Journal of Multidisciplinary International Studies, vol. 8 no. 2

Kaw, Eugenia (1997) Medicalization of Racial Features: Asian American Women and Cosmetic Surgery, Medical Anthropology Quarterly, New Series 7(1): 74-89.

Kress, G. (1998) 'Visual and verbal modes of representation in electronically mediated communication: the potentials of new forms of text'. In I. Snyder (ed). Page to Screen, Taking Literacy into the Electronic Era. London: Routledge. Pp. 53-79.

Kress, G. and Van Leeuwen, T. (2006) Reading Images: The Grammar of Visual Design, 2nd edition, London, Routledge

Miller, D. (2000) The fame of Trinis: websites as traps, Journal of Material Culture 5: 524.

Molotch, H. (2005) Where Stuff Comes From (New York: Routledge)

Papadopoulos, N. (2011) Of places and brands, in Pike, A. (ed.) (2011) Brands and Branding Geographies (Cheltenham: Edward Elgar) pp. 25-43. 
Pike, A. (ed.) (2011) Brands and Branding Geographies (Cheltenham: Edward Elgar) Rakic, T. and Chambers, D. (eds) An Introduction to Visual Research Methods in Tourism (Abingdon: Routledge)

Reisman, D. (2010) Health Tourism: Social Welfare through International Trade. Cheltenham: Edward Elgar.

Rojek, C. (1997) Indexing, dragging and the social construction of tourism sights, in C. Rojek and J. Urry (eds) Touring Cultures: transformations of travel and theory (London: Routledge) pp. 23-51.

Sanchez Taylor, J. (2011) 'Cosmetic Surgery or Beauty Treatments: Cosmetic Surgery and Young Women in the UK' at the BSA Medical Sociology Group Annual Conference, University of Chester.

Schult, J. (2006) Beauty from Afar (New York: Stewart, Tabori \& Chang)

Skeggs, B (2003) Class, Self, Culture: London: Routledge.

Van Dijk, T. A. (2001) 'Critical Discourse Analysis' in D. Tannen, D. Schiffrin \& H. Hamilton (Eds.), Handbook of Discourse Analysis. (pp. 352-371). Oxford: Blackwell

Ward, K. (2010) Towards a relational comparative approach to the study of cities, Progress in Human Geography 34(4): 471-487.

Wilson, A. (2011) Foreign bodies and national scales: medical tourism in Thailand, Body \& Society 17: 121-37.

Wilson, T. and Rahman, A. (2004) The tourist gaze goes on-line: Rojak (hybrid) reception theory structures and ludic looking at/from Malaysia, Tourist Studies 4: 69-92.

Woo, Keun Ja (2004), 'The Beauty Complex and the Cosmetic Surgery Industry', Korea Journal, 44 (2): 52-82. 


\section{Websites}

\section{Spanish Websites}

http://www.cirumed.es/

http://www.millsmedical.com/marbella spain.asp

http://www.oceanclinic.net/plastic-surgery/

http://netdoctor.privatehealth.co.uk/cosmetic-surgery/cosmetic-abroad/spain/

\section{Thai Websites}

http://www.somniomedical.com/

www.mybodyandspirit.com.au

\section{Czech Republic Websites}

www.beautifulbeings.co.uk

www.laderma.com 